Supporting Information

\title{
Improving Charge Collection from Colloidal Quantum Dot Photovoltaics by Single-Walled Carbon Nanotube Incorporation
}

Jonghee Yang, Jongtaek Lee, Junyoung Lee, and Whikun Yi*

Research Institute for Natural Sciences and Department of Chemistry, Hanyang University, Seoul 04763, Republic of Korea

*Corresponding Author. Tel: +82-2-2220-0931, E-mail: wkyi@hanyang.ac.kr 


\section{EXPERIMENTAL SECTION}

\section{Materials}

Lead (II) oxide (PbO) (trace metal basis, $99.999 \%$ ), OA (technical grade, $90 \%$ ), 1-octadecene (ODE) (technical grade, $90 \%$ ), hexamethyldisilathiane $\left(\mathrm{TMS}_{2} \mathrm{~S}\right)$ (synthesis grade), zinc acetate (trace metal basis, $99.99 \%$ ), tetramethylammonium hydroxide pentahydrate (TMAH) (97\%), ethanolamine (99.0\%), TBAI (99.0\%), EDT (98.0\%), dimethyl sulfoxide (99.9\%), and acetonitrile (+99.8\%), were purchased from Sigma-Aldrich. SWNT produced by the arcdischarge method was purchased from Hanhwa Nanotech Inc. (ASP-100F), and C60 (> 99.5 \%) was purchased from Tokyo Chemical Industry Co., Ltd.

\section{Encapsulation of $\mathrm{C}_{60}$ molecules inside SWNTs}

$\mathrm{C}_{60}$ molecules were encapsulated inside SWNTs according to a previously reported method. ${ }^{1,2}$ Prior to the $\mathrm{C}_{60}$ encapsulation, as-purchased SWNT bundles were purified by annealing at $400{ }^{\circ} \mathrm{C}$ for $4 \mathrm{hrs}$ under dry air to remove their terminating caps. The pristine SWNT bundles were placed in a Pyrex tube with $\mathrm{C}_{60}$ molecules, and the tube was sealed at a pressure of $1 \times 10^{-6}$ Torr. The isolated tube was heated in a furnace at $480{ }^{\circ} \mathrm{C}$ for $12 \mathrm{hrs}$. The resulting bundles were taken out after the tube was cooled to room temperature. The bundles were washed with ethanol and toluene by ultrasonication for $6 \mathrm{hrs}$ to thoroughly dissolve the $\mathrm{C}_{60}$ molecules adsorbed on the SWNT surface. For precise comparison, the same procedure (high vacuum sealing and thermal annealing) was executed in the case of pristine SWNT bundles which lacked $\mathrm{C}_{60}$ molecules in the tube.

\section{Synthesis of PbS CQDs and SWNT (or C60@SWNT) incorporation}


PbS CQDs were synthesized based on the method reported by Hines et al. but with a slight modification. ${ }^{3} \mathrm{PbO}(0.45 \mathrm{~g}), \mathrm{OA}(1.3 \mathrm{~mL})$, and $\mathrm{ODE}(18 \mathrm{~mL})$, were mixed in a three-neck flask connected to a Schlenk line and heated to $100{ }^{\circ} \mathrm{C}$ under vacuum for $2 \mathrm{hrs}$. The flask was then cooled to $90{ }^{\circ} \mathrm{C}$ and maintained at that temperature in an Ar atmosphere for $2 \mathrm{hrs}$. Subsequently, $\mathrm{TMS}_{2} \mathrm{~S}(210 \mu \mathrm{L})$ dissolved in ODE $(10 \mathrm{~mL})$ was quickly injected into the flask. After $1 \mathrm{~min}$, the flask was quickly cooled to room temperature. The products were precipitated with acetone and centrifuged at $8000 \mathrm{rpm}$ for $20 \mathrm{~min}$. After centrifugation, the supernatant was removed and the precipitated CQDs were re-dispersed in heptane. The CQD dispersion was then precipitated with acetone and centrifuged at $8000 \mathrm{rpm}$ for $20 \mathrm{~min}$. The supernatant was removed again, and the product was dried with flowing $\mathrm{N}_{2}$. The resulting CQD precipitates were re-dispersed in heptane $\left(50 \mathrm{mg} \mathrm{mL}^{-1}\right.$ ) for the thin film fabrication. The SWNT species were incorporated by the addition of an appropriate volume of SWNT (or $\left.\mathrm{C}_{60} @ \mathrm{SWNT}\right)$ dispersion $\left(0.01 \mathrm{mg} \mathrm{mL}^{-1}\right.$ in toluene) to the prepared CQD dispersion (after filtration using a syringe filter, pore size: $450 \mathrm{~nm}$ ) to achieve the desired concentration of $\mathrm{PbS}$ CQDs $\left(25 \mathrm{mg} \mathrm{mL}^{-1}\right)$.

\section{Synthesis of ZnO NPs}

A previously reported method used to prepare ZnO NPs was followed with a slight modification. ${ }^{4}$ A zinc acetate $(0.5504 \mathrm{~g})$ solution in dimethyl sulfoxide $(30 \mathrm{~mL})$ and TMAH $(0.9995 \mathrm{~g})$ solution in ethanol $(10 \mathrm{~mL})$ were mixed dropwise and stirred for $24 \mathrm{~h}$ under ambient conditions. Ethyl acetate was then added, and the resultant opaque dispersion was centrifuged at $8000 \mathrm{rpm}$ for 20 min. After removal of the supernatant, ethanolamine $(200 \mu \mathrm{L})$ and ethanol $(1 \mathrm{~mL})$ were added to stabilize the NPs. The NPs were washed again with ethyl acetate and centrifuged at $8000 \mathrm{rpm}$ for $20 \mathrm{~min}$. Then, the supernatant was removed again. The resulting ZnO NPs were dried with flowing 
$\mathrm{N}_{2}$ and re-dispersed in ethanol. The dispersion was filtered through a membrane filter (pore size: $100 \mathrm{~nm}$ ), and the concentration was adjusted to $20 \mathrm{mg} \mathrm{mL}^{-1}$ for the $\mathrm{ZnO} \mathrm{NP}$ layer fabrication.

\section{Fabrication of CQDPVs}

The $\mathrm{ZnO}$ NP layer was prepared by spin coating at $2000 \mathrm{rpm}$ for $20 \mathrm{~s}$ on prepatterned ITO substrates, followed by annealing at $250{ }^{\circ} \mathrm{C}$ for $20 \mathrm{~min}$ in ambient air. The $\mathrm{PbS} \mathrm{CQD}$ layers were fabricated via a layer-by-layer spin coating process in ambient air. TBAI-PbS CQD layers were prepared as follows: the presynthesized OA-PbS CQDs were deposited by spin coating at 2000 rpm for $15 \mathrm{~s}$. Subsequently, a TBAI solution $\left(10 \mathrm{mg} \mathrm{mL}^{-1}\right.$ in methanol) was added to fully cover the substrate for $30 \mathrm{~s}$, followed by spinning of the substrate at $2000 \mathrm{rpm}$ for $15 \mathrm{~s}$. Two washing steps were performed via spin coating pure methanol onto the TBAI-treated CQD substrates. The same processes were repeated seven times to achieve the appropriate thickness of the TBAI-PbS CQD layer. EDT-treated PbS CQD layers were added to the TBAI-PbS CQD layer as follows: PbS CQD dispersions for the EDT-PbS layer fabrication (with and without SWNT or $\mathrm{C}_{60} @ \mathrm{SWNT}$, $25 \mathrm{mg} \mathrm{mL}^{-1}$ of PbS CQDs in heptane/toluene 1:1 solvent) were loaded and spin-coated at 2000 rpm for $15 \mathrm{~s}$. To prevent the aggregation of SWNT species, continuous sonification was applied to the dispersions during the overall EDT-PbS CQD layer deposition. Subsequently, 0.01 vol.\% EDT solution (in acetonitrile) was loaded onto the substrate for $30 \mathrm{~s}$, followed by spinning at 2000 rpm for $15 \mathrm{~s}$. The CQDs were washed three times with pure acetonitrile by spin coating under the same conditions. The same procedures were repeated to obtain complete CQD layers (two layers of EDT-PbS CQD onto seven layers of TBAI-PbS). To achieve only TBAI-PbS CQD deposition, the CQD dispersions were loaded through a syringe filter (pore size: $450 \mathrm{~nm}$ ). Patterned Au electrodes were deposited onto the substrate with a shadow mask to achieve an active area of 0.075 
$\mathrm{cm}^{2}$ by a radio-frequency magnetron sputtering system under a base pressure of $2.0 \times 10^{-6}$ Torr. For the EDT-PbS CQD films, 4 layers of EDT-PbS films were spin-coated via the same procedures.

\section{Material characterization}

The structure of the pristine SWNT, $\mathrm{C}_{60} @ S W N T$, EDT-PbS CQDs and the EDT-PbS matrix incorporating the SWNT species, were taken by TEM (JEOL, JEM-2100F and JEM-F200) at an acceleration voltage of $200 \mathrm{kV}$. To acquire the TEM images of pristine SWNTs and C60@SWNTs, $10 \mu \mathrm{L}$ of each dispersion was drop-casted onto the TEM grid with a lacey carbon film (Ted pella, 01895-F). Continuous sonication was applied to the dispersions just before the drop-casting. The resulting grids were dried under vacuum $\left(2.0 \times 10^{-3}\right.$ Torr $)$ for $4 \mathrm{hrs}$ prior to TEM measurement. To obtain the TEM images of a SWNT- (or $\mathrm{C}_{60} @ \mathrm{SWNT}$-) incorporated EDT-PbS CQD matrix, a stock dispersion (0.005 and 0.040 wt.\% of SWNTs or $\mathrm{C}_{60} @$ SWNTs with respect to PbS CQDs)

was diluted to $5 \mathrm{mg} \mathrm{mL}^{-1}$ using a heptane/toluene solvent and spin-coated on to the carbon-coated TEM grid (Ted pella, 01814-F) at $3000 \mathrm{rpm}$ for $15 \mathrm{~s}$. Here, the TEM grids were first fixed onto an ITO substrate. Continuous sonication was applied to the dispersions just before loading the dispersion. After that, 0.01 vol.\% EDT solution (in acetonitrile) was loaded onto the grid for $30 \mathrm{~s}$, followed by spinning at $2000 \mathrm{rpm}$ for $15 \mathrm{~s}$. The CQDs films on the TEM grid were washed three times with pure acetonitrile by spin coating using the same conditions. After the deposition, the grids were carefully detached from the substrate and dried under vacuum $\left(2.0 \times 10^{-3}\right.$ Torr $)$ for 4 hrs. The Raman spectra of the SWNT species were acquired by the Raman microscope (Kaiser optical system, HoloLab 5000). Optical images of the EDT-PbS CQD surfaces were acquired using an optical microscope (Olympus BX51 TR-N33MU). Surface morphology images of the EDT-PbS CQD surfaces were obtained using a Park Systems XE-100 atomic force microscope. UV/Vis 
absorption spectra were measured using a Mecasys Optizen 2120 UV spectrophotometer. UPS spectra were collected using a Theta Probe photoelectron spectrometer (Thermo Fisher Scientific). UPS measurements were performed with a $\mathrm{He} \mathrm{I}(21.22 \mathrm{eV})$ source under a base pressure of $8 \times 10^{-7}$ Torr while applying a $-9 \mathrm{~V}$ bias to the samples. Steady-state PL spectra and TRPL decay profiles were collected using a Fluorolog-3 luminescence spectrometer (Horiba Jobin Yvon). The excitation and emission wavelengths for TRPL measurements were fixed at $467 \mathrm{~nm}$ and $1080 \mathrm{~nm}$, respectively. The surface images of the SWNT-incorporated CQD film were acquired with the SEM (FEI Verios G4 UC).

\section{CQDPV characterization}

The cross-sectional images of CQDPVs were acquired by the SEM (FEI Nova NanoSEM 450). All electrical characterizations were performed under ambient conditions. The $J-V$ curves of the CQDPVs were measured using a Keithley 2400 sourcemeter with 1 sun AM 1.5 illumination (100 $\mathrm{mW} / \mathrm{cm}^{2}$ ) with a class AAA solar simulator (McScience K201 LAB 55) calibrated with a standard Si reference solar cell (McScience K801S-B041). A black shadow mask $\left(0.06 \mathrm{~cm}^{2}\right)$ was used to exclude the possibility of overestimation. The IPCEs of the CQDPVs were measured using an IPCE measurement system (McScience K3100 IQX). Photo-CELIV transients were recorded on a custom-built setup which consisted of a wavelength-tunable pulsed Nd:YAG laser source (OPOTEK VIBRANT $355 \mathrm{LD}$, repetition rate of $10 \mathrm{~Hz}$ and pulse width of $5 \mathrm{~ns}$ ), a function

generator (Agilent 33220A), a delay generator (Quantum Composers 9520), and a digital oscilloscope (Agilent DSO3202A) with a $50 \Omega$ input terminal resistance. The laser pulse and the offset voltage were fixed at $532 \mathrm{~nm}$ and $0.5 \mathrm{~V}$, respectively, for all photo-CELIV measurements. The ramp rate was $2 \mathrm{~V} / 50 \mu \mathrm{s}$ for the CQDPVs and $1 \mathrm{~V} / 50 \mu$ s for the EDT-PbS CQD films. To 
block the electron transport during the photo-CELIV measurements, $\mathrm{Al}_{2} \mathrm{O}_{3}$ insulating layers (thickness of $20 \mathrm{~nm}$ ) were deposited on to the ITO substrate and ZnO NPs-coated ITO substrate by atomic layer deposition. TPV measurements were conducted using the same photo-CELIV measurement system with the addition of extra light output from a Xe lamp as a continuous illumination source for $V_{\mathrm{OC}}$ generation. A small perturbation of a laser pulse of $532 \mathrm{~nm}$ wavelength was applied on the CQDPVs with a repetition rate of $10 \mathrm{~Hz}$ and a pulse width of $5 \mathrm{~ns}$. An oscilloscope with an input terminal of $1 \mathrm{M} \Omega$ was used to record the TPV signals, which were averaged at least 200 times. The Mott-Schottky (capacitance-voltage) measurements were obtained using an impedance analyzer (IviumTech Iviumstat). An AC signal with an amplitude of $20 \mathrm{mV}$ and a frequency of $1 \mathrm{kHz}$ was applied whereas the DC voltage was swept from -1 to $1 \mathrm{~V}$. All capacitance measurements were performed with 16 samples for each type of CQDPVs, and the results were averaged.

\section{Depletion width calculation from the Mott-Schottky plot}

The depletion width $\left(W_{\mathrm{D}}\right)$ in CQDPVs at a short-circuit condition of operation was calculated using the following equation, ${ }^{5}$

$$
W_{\mathrm{D}}=\frac{1}{N_{\mathrm{CQD}}} \sqrt{\frac{2 \varepsilon_{0} \varepsilon_{\mathrm{CQD}}\left(V_{\mathrm{bi}}-V\right)}{q\left(\frac{1}{N_{\mathrm{CQD}}}+\frac{1}{N_{\mathrm{ZnO}}}\right)}}
$$

where $\varepsilon_{\mathrm{CQD}}$ is the dielectric constant of the PbS CQD film (18.8), and $N_{\mathrm{CQD}}$ and $N_{\mathrm{ZnO}}$ are the doping densities of the PbS CQD and ZnO NP layers, respectively. The value of $N \mathrm{ZnO}, 1.0 \times 10^{17} \mathrm{~cm}^{-3}$, was obtained from the literature. ${ }^{6}$ 
The values of $N_{\mathrm{CQD}}$ were obtained by fitting the linear slope region of the Mott-Schottky plot using the following equation. ${ }^{7,8}$

$$
\frac{1}{C^{2}}=\frac{2\left(V_{\mathrm{bi}}-V\right)}{A^{2} q \varepsilon_{\mathrm{CQD}} \varepsilon_{0} N_{\mathrm{CQD}}}
$$

The calculated values of $N_{\mathrm{CQD}}$ were $8.71 \times 10^{15}, 8.37 \times 10^{15}$, and $7.90 \times 10^{15} \mathrm{~cm}^{-3}$ for the control, SWNT- and C60@SWNT-incorporated CQDPVs, respectively. By substituting all of the physical values in Equation S4, the respective values of $W_{\mathrm{D}}$ were estimated to be 148.9, 150.7, and 153.2 nm. 


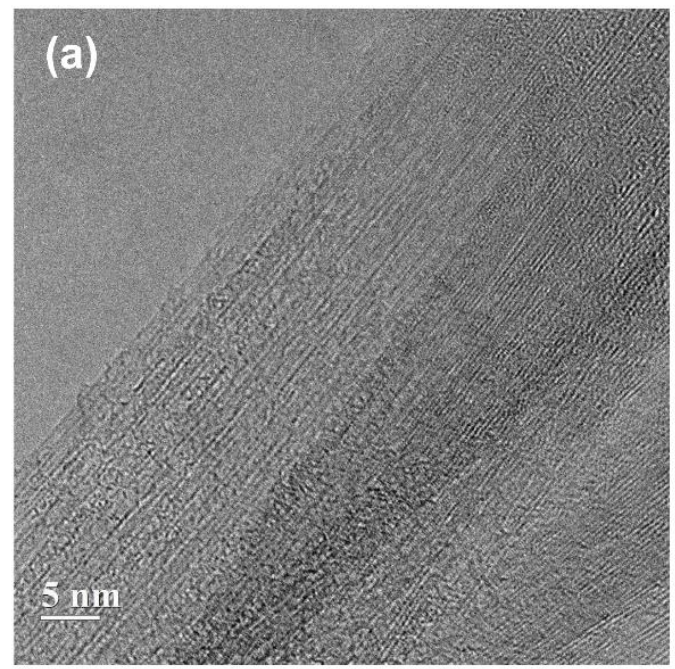

(b)

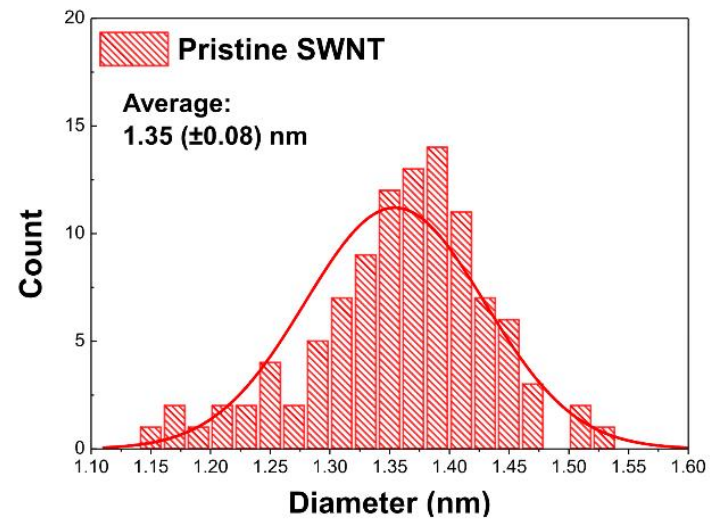

Figure S1. (a) A representative TEM image of pristine SWNT bundles. (b) The diameter distribution of the pristine SWNTs estimated from the 105 individual tubes. The average diameter of the pristine SWNT was estimated to $1.35( \pm 0.08) \mathrm{nm}$. 

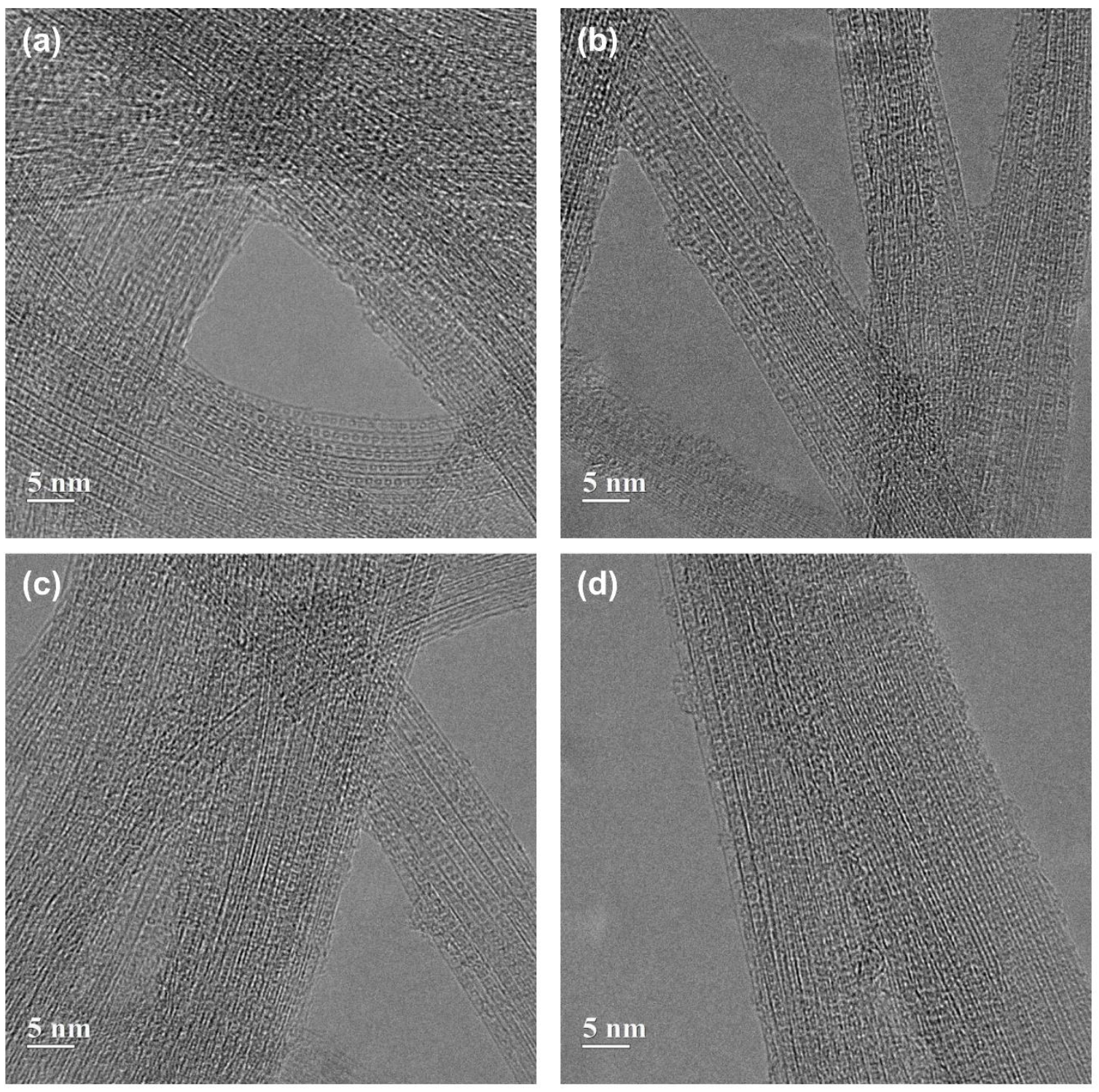

(e)

(f)
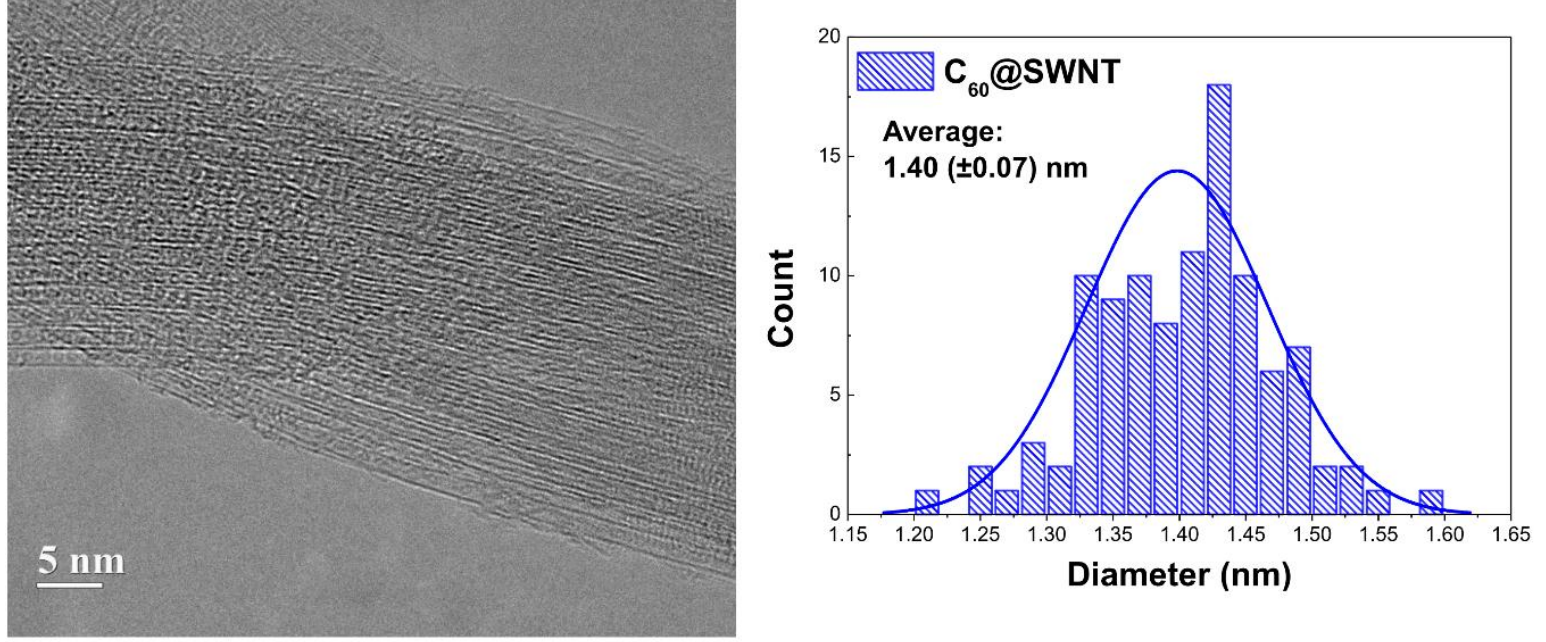
Figure S2. High-resolution TEM images of $\mathrm{C}_{60} @$ SWNT bundle at five different locations (a-e). In all cases, circular $\mathrm{C}_{60}$ molecules are completely filled inside of the SWNTs. (f) The diameter distribution of the $\mathrm{C}_{60} @$ SWNTs estimated from the 105 individual tubes. The average diameter of C60@SWNT was estimated to $1.40( \pm 0.07)$ nm. 
(a)

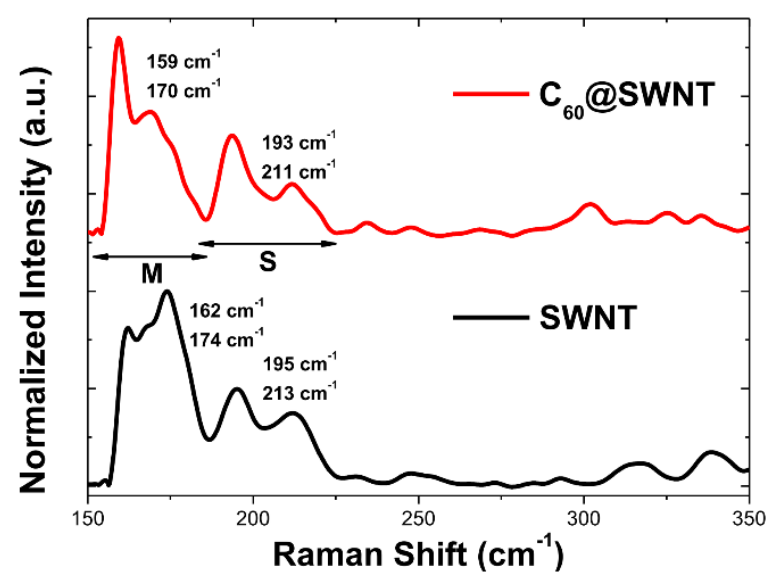

(b)

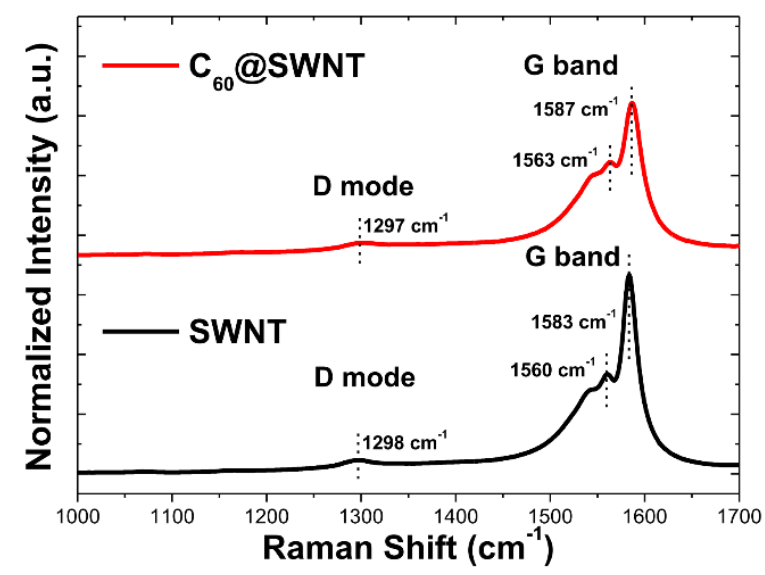

Figure S3. Raman spectra of the pristine SWNT (black) and $\mathrm{C}_{60} @$ SWNT (red) bundles used in this study: (a) RBM and (b) D and G band regions. 


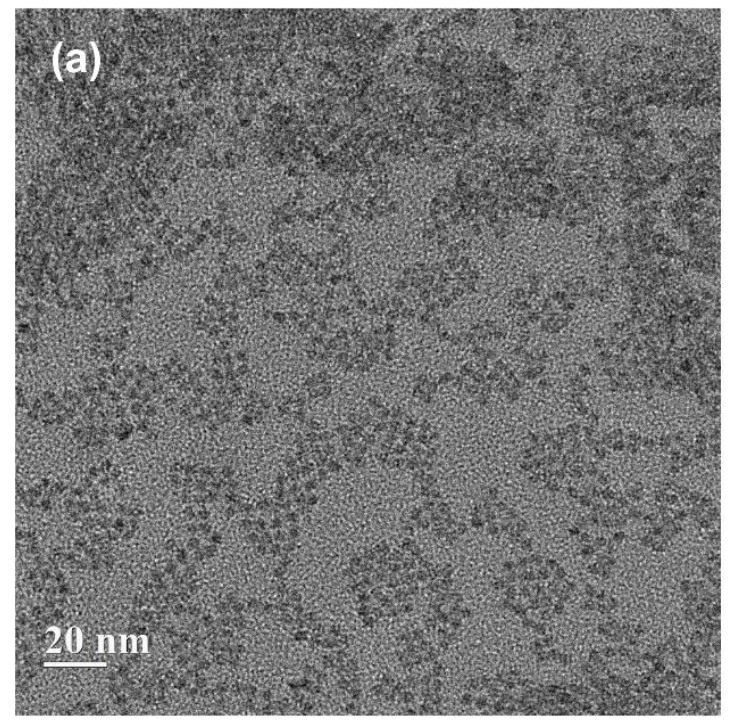

(b)

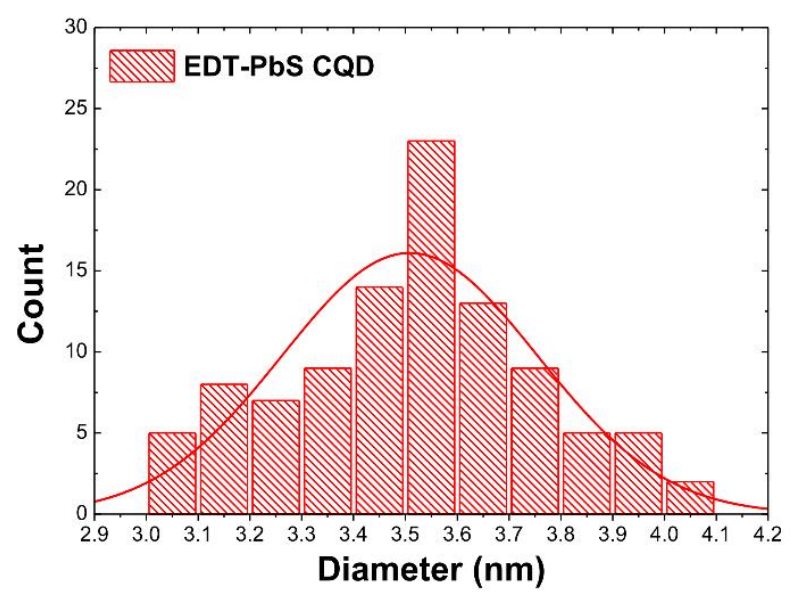

Figure S4. (a) TEM image and (b) the size distribution of the EDT-PbS CQDs. The average diameter of the CQD was estimated to be $3.51( \pm 0.25) \mathrm{nm}$. 

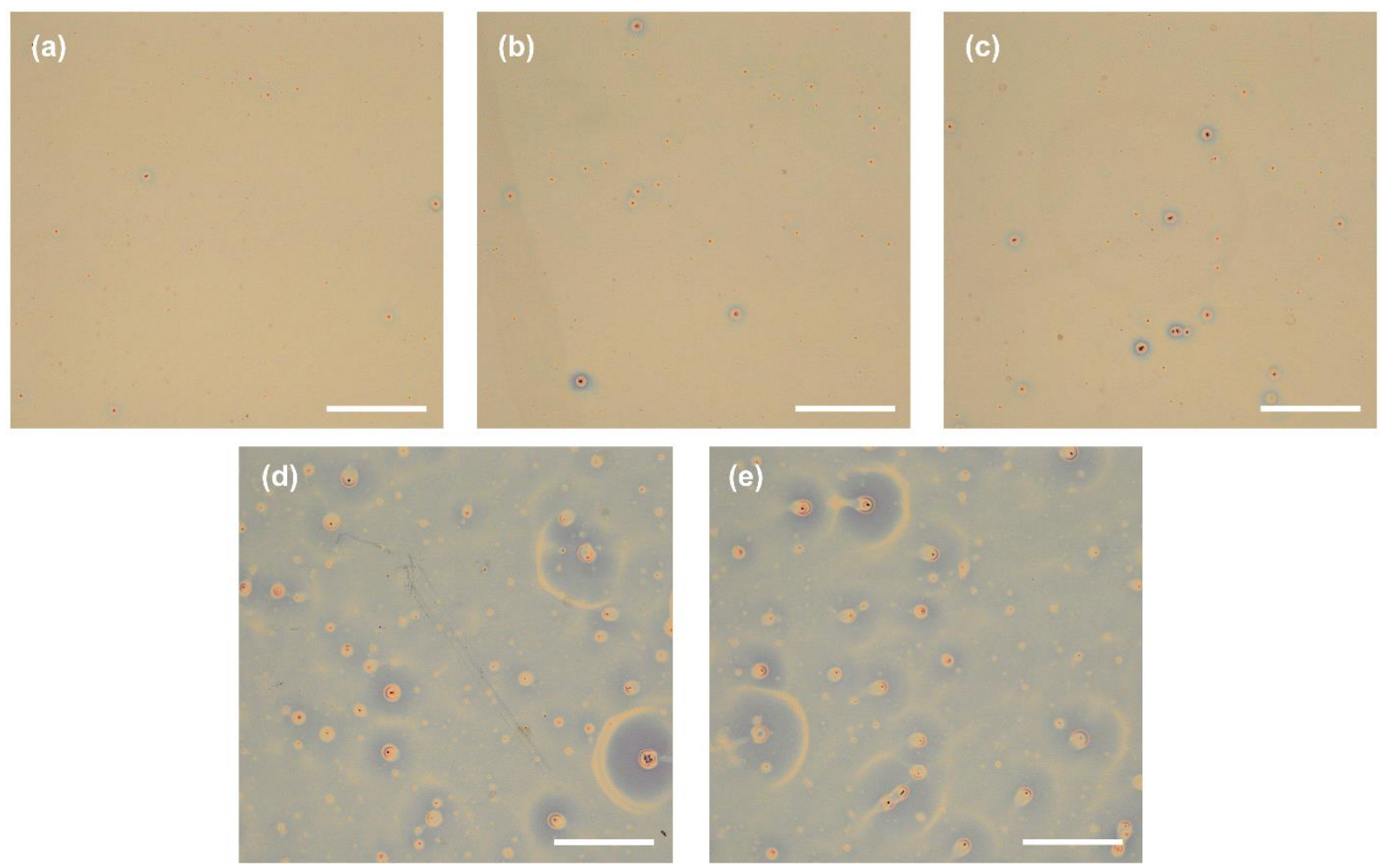

Figure S5. Optical microscopy images of various EDT-PbS CQD layers: (a) control (EDT-PbS CQD only), EDT-PbS CQD layers incorporating (b) 0.005 wt.\% pristine SWNT, (c) 0.005 wt.\% C60@SWNT, (d) 0.040 wt.\% pristine SWNT, and (e) 0.040 wt.\% C60@SWNT. Scale bar: $500 \mu \mathrm{m}$. 
(a)

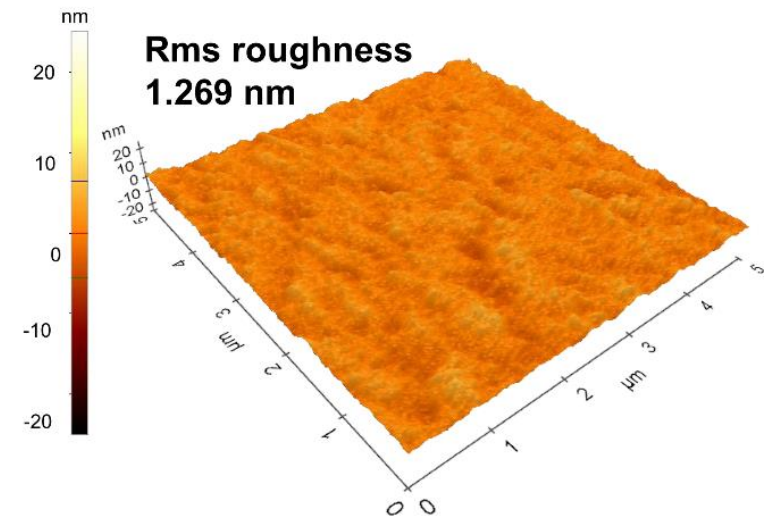

(c)

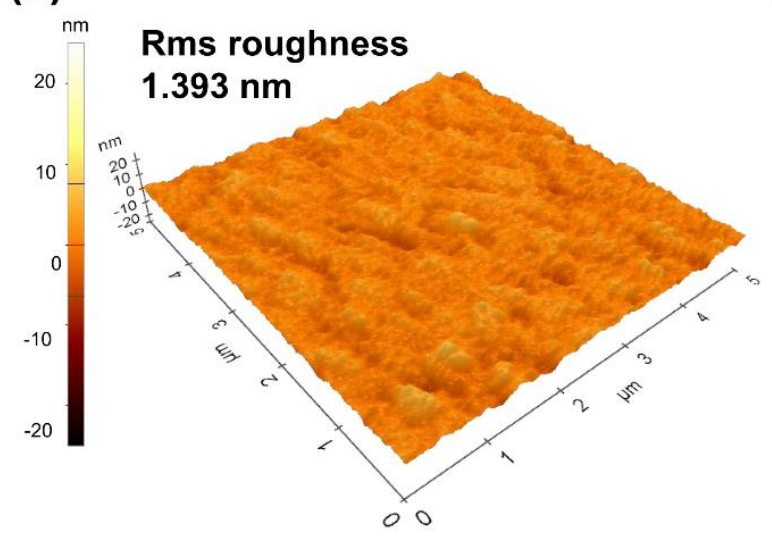

(b)

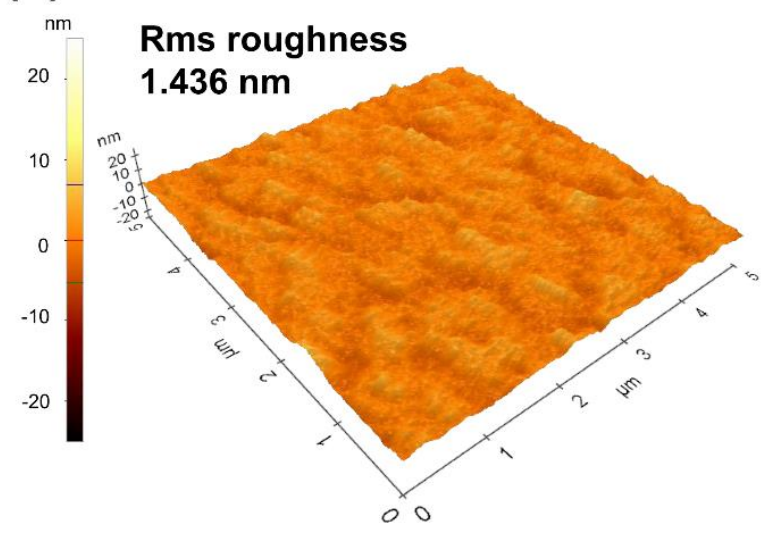

(d)

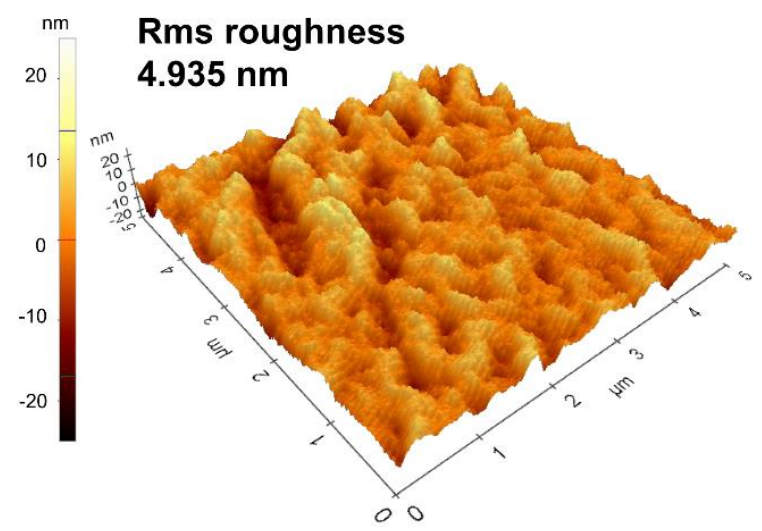

(e)

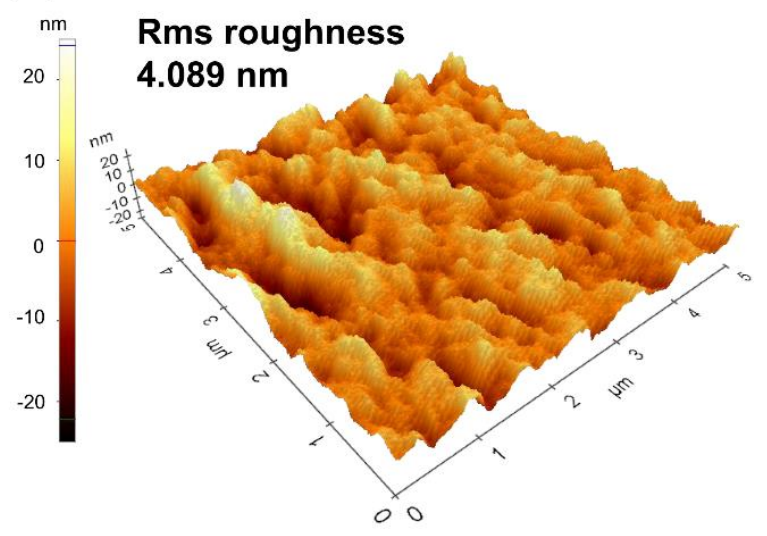

Figure S6. AFM topographic profiles of various EDT-PbS CQD layers: (a) control (EDT-PbS CQD only), EDT-PbS CQD layers incorporating (b) 0.005 wt.\% pristine SWNT, (c) 0.005 wt.\% C60@SWNT, (d) 0.040 wt.\% pristine SWNT, and (e) 0.040 wt.\% C60@SWNT. 

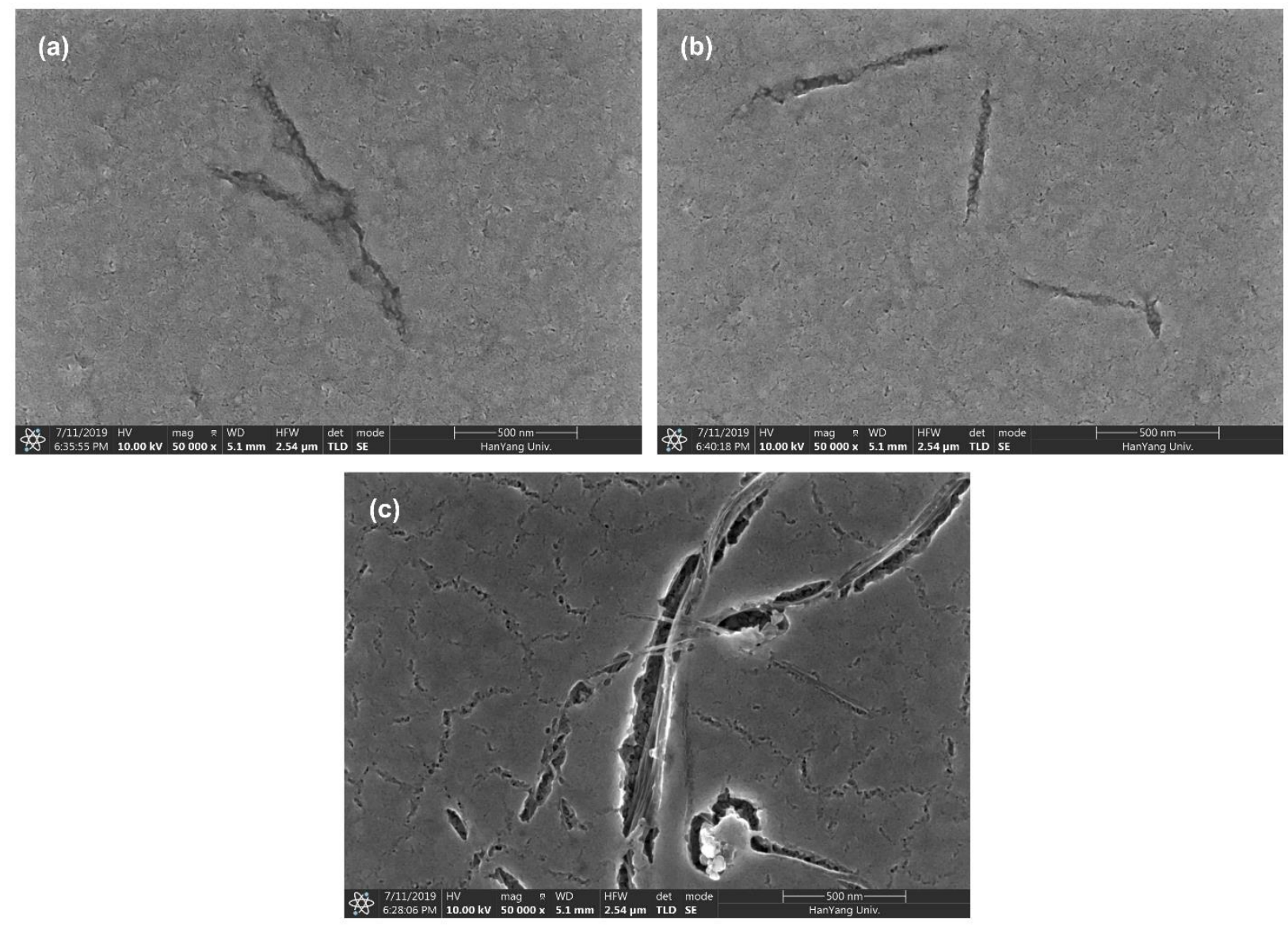

Figure S7. Surface SEM images of a (a) control EDT-PbS CQD layer and EDT-PbS CQD layers incorporating (b) $0.005 \mathrm{wt} . \%$ and (c) $0.040 \mathrm{wt} . \%$ SWNTs. All of the CQD layers were spin-coated onto ITO substrates. 

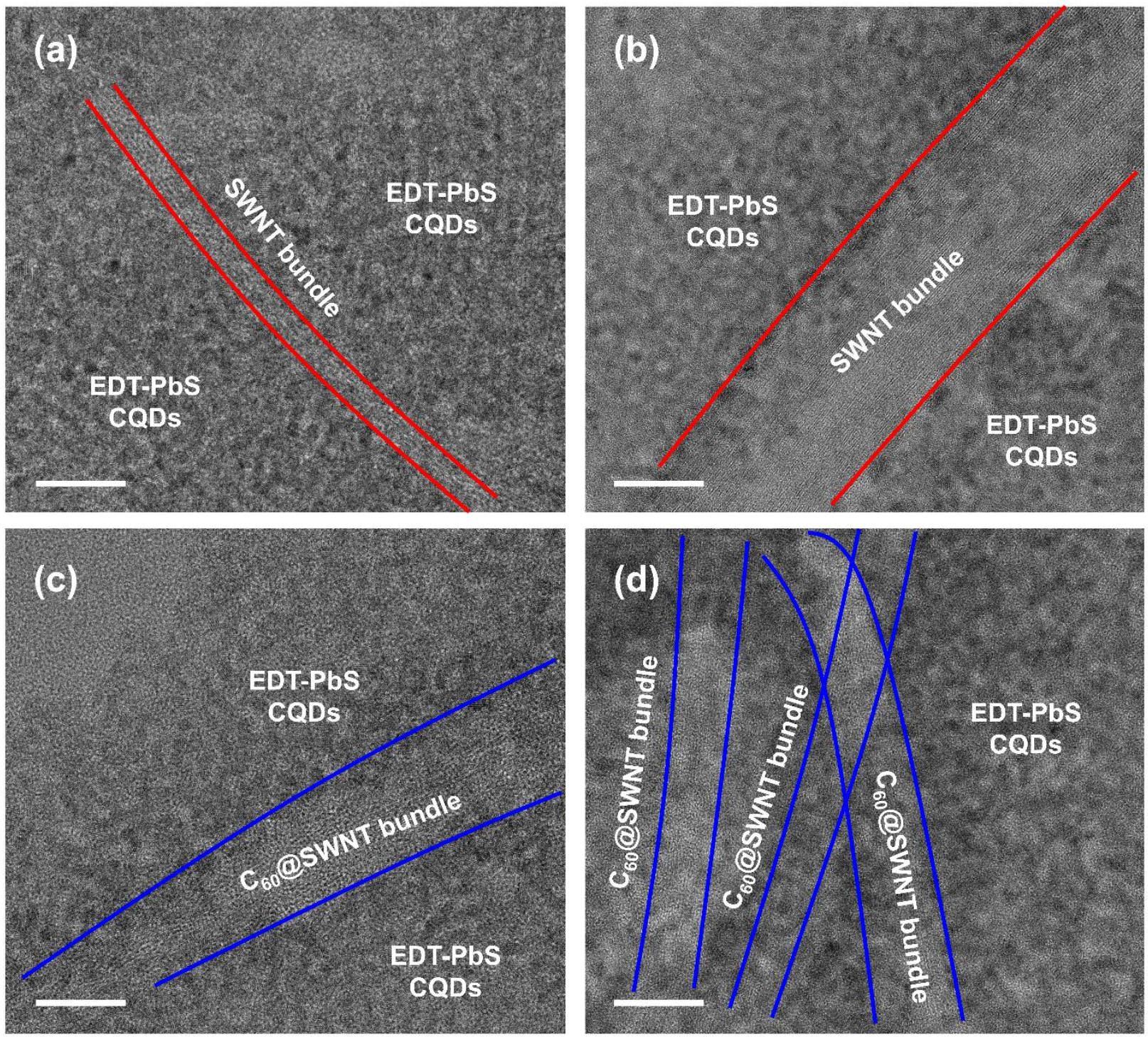

Figure S8. TEM images of CQD matrices incorporating $(a, b)$ SWNT and (c, d) C60@SWNT bundles (scale bar: $20 \mathrm{~nm}$ ). The red and blue lines roughly indicate the border between the SWNT (or $\mathrm{C}_{60} @ \mathrm{SWNT}$ ) bundles and the EDT-PbS CQDs. 

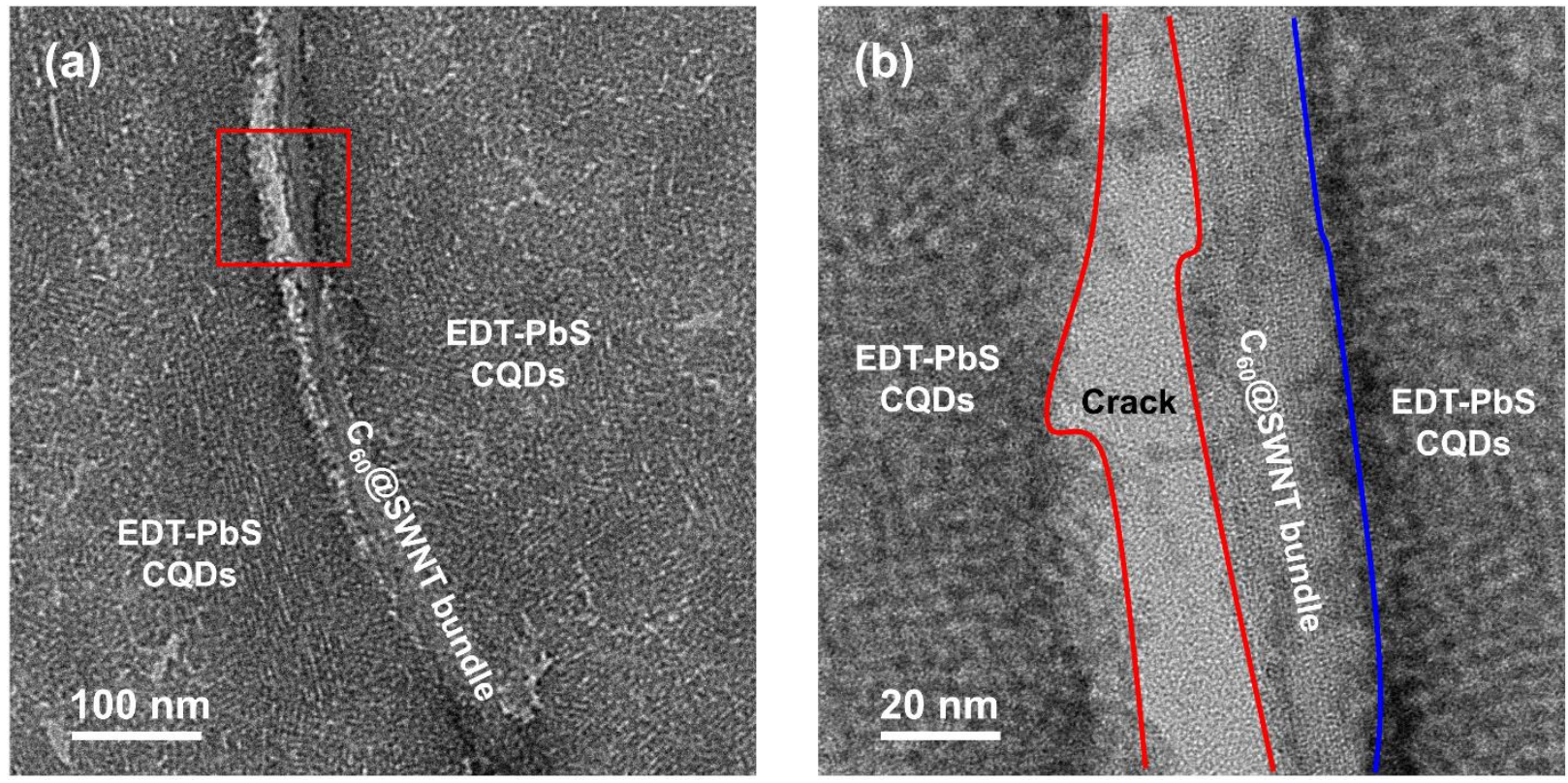

Figure S9. TEM images of CQD matrices incorporating 0.040 wt.\% of $\mathrm{C}_{60} @ \mathrm{SWNT}$. At the low magnification image (a), both the macroscopic void along the $\mathrm{C}_{60} @$ SWNT bundle and the microscopic cracks away from the SWNT aggregates were observed. At the high magnification image (b), a separation of EDT-PbS CQ matrix from the incorporated C60@SWNT bundle is

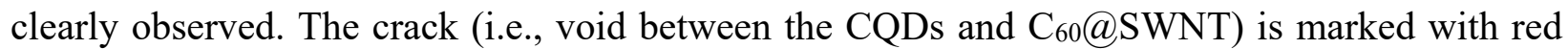
lines while the contact border between the CQDs and the bundle is marked with blue line. 


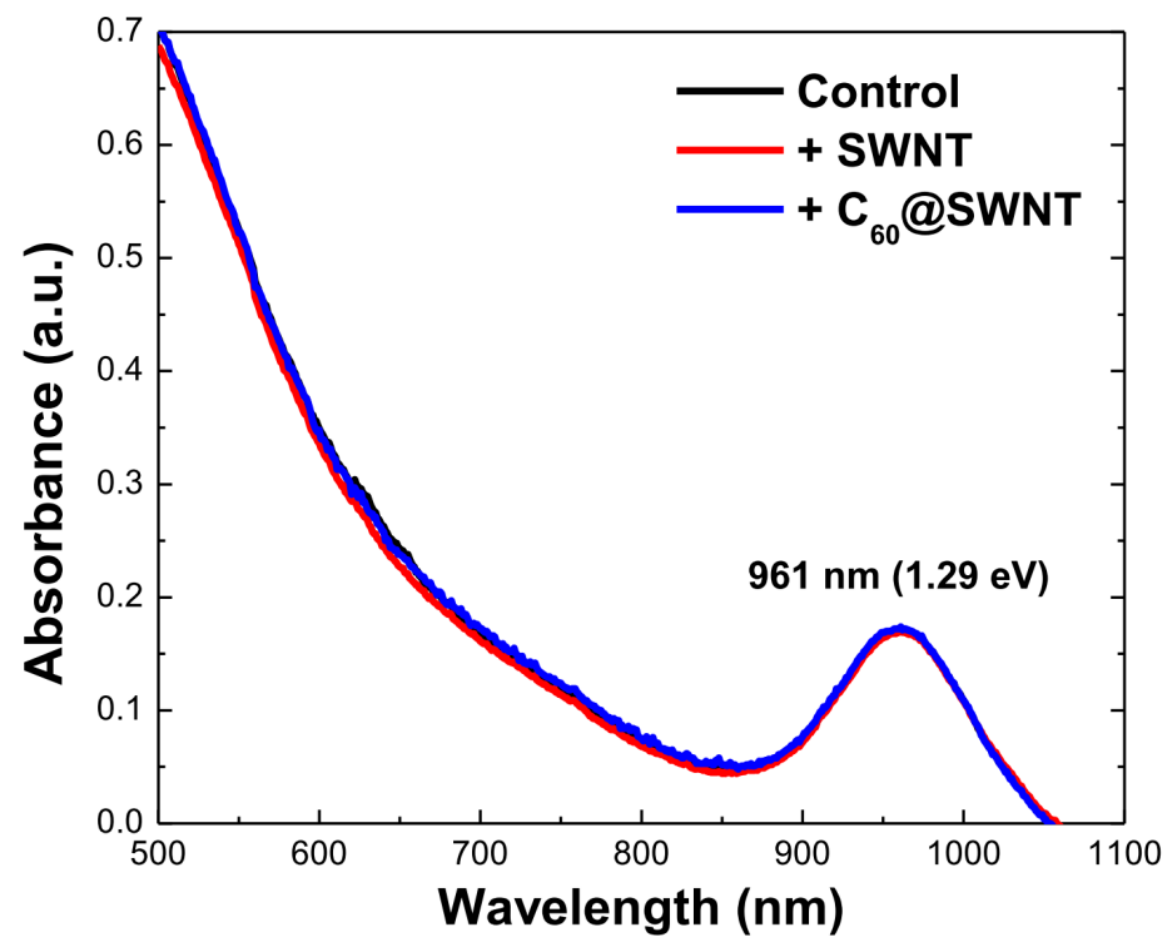

Figure S10. UV/Vis absorption spectra of the EDT-PbS CQD films 


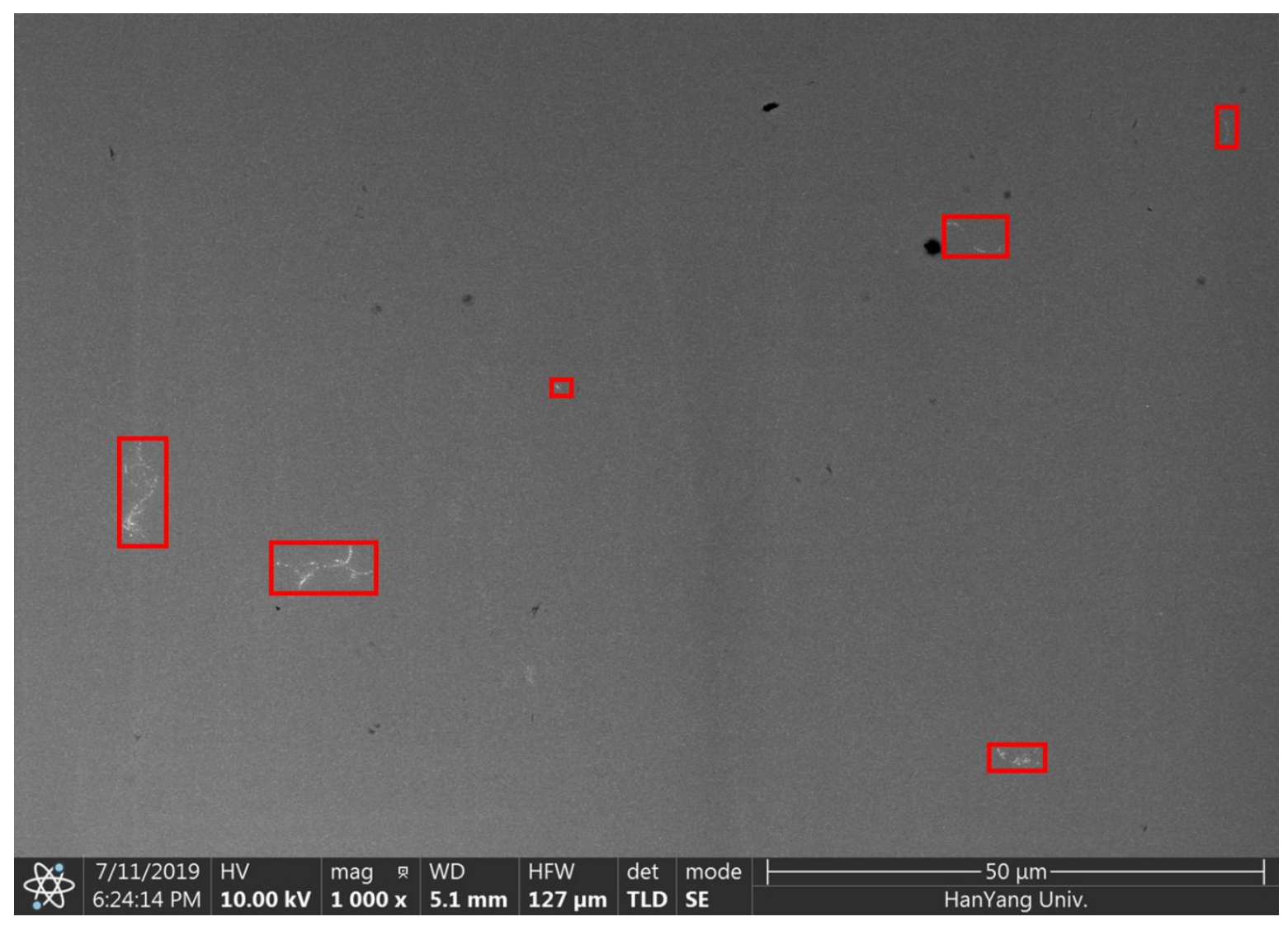

Figure S11. Low magnification surface SEM image of the EDT-PbS CQD film incorporating 0.040 wt.\% SWNTs spin-coated onto the ITO substrate. The areas marked with red rectangles indicate the site of SWNT aggregates. The portion of this area with respect to the entire surface was calculated to be $1.46 \%$. 


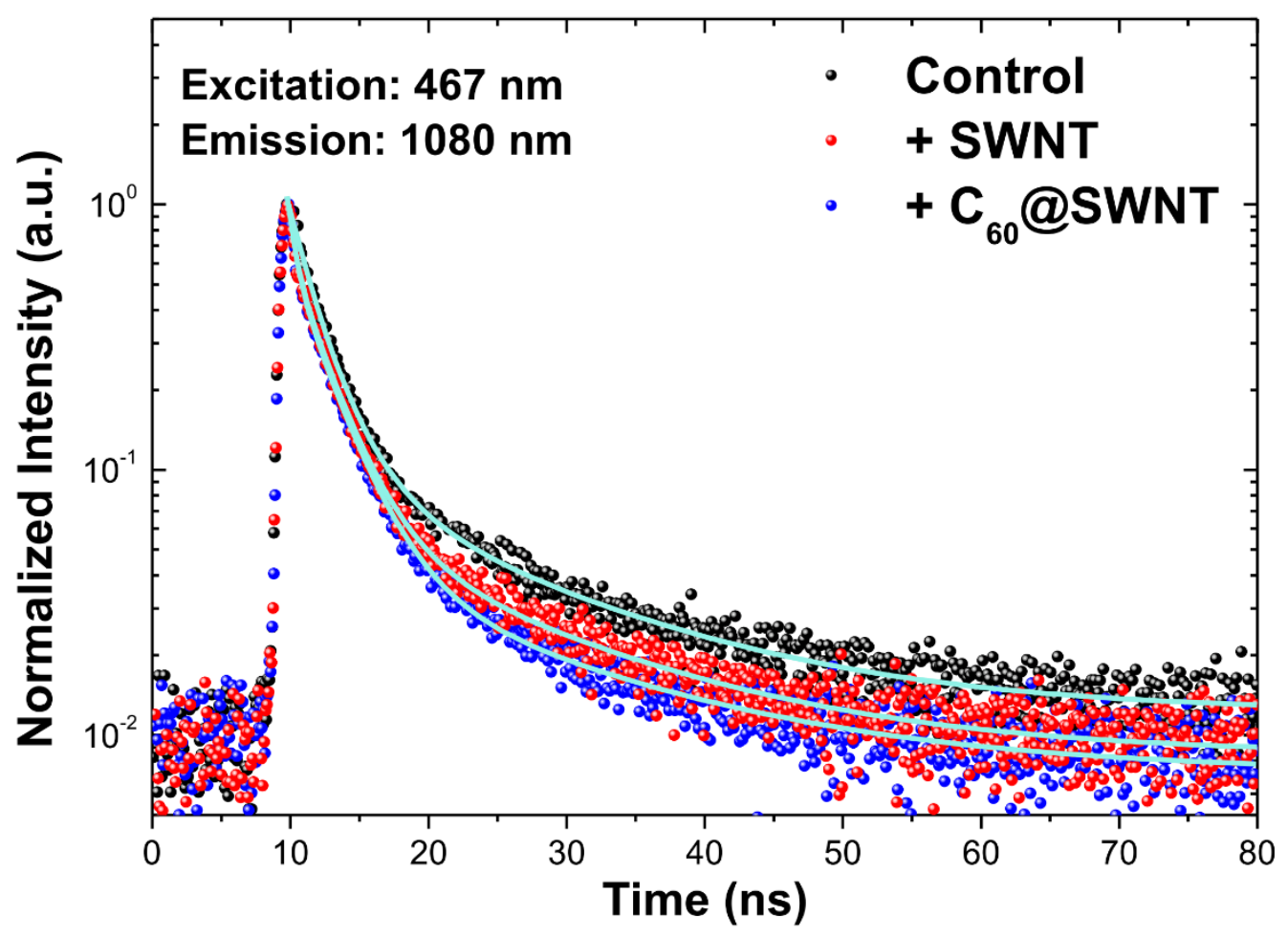

Figure S12. Time-resolved photoluminescence decay profiles of the EDT-PbS CQD layers. For each spectrum, the data was fitted with a tri-exponential decay model (solid lines). 


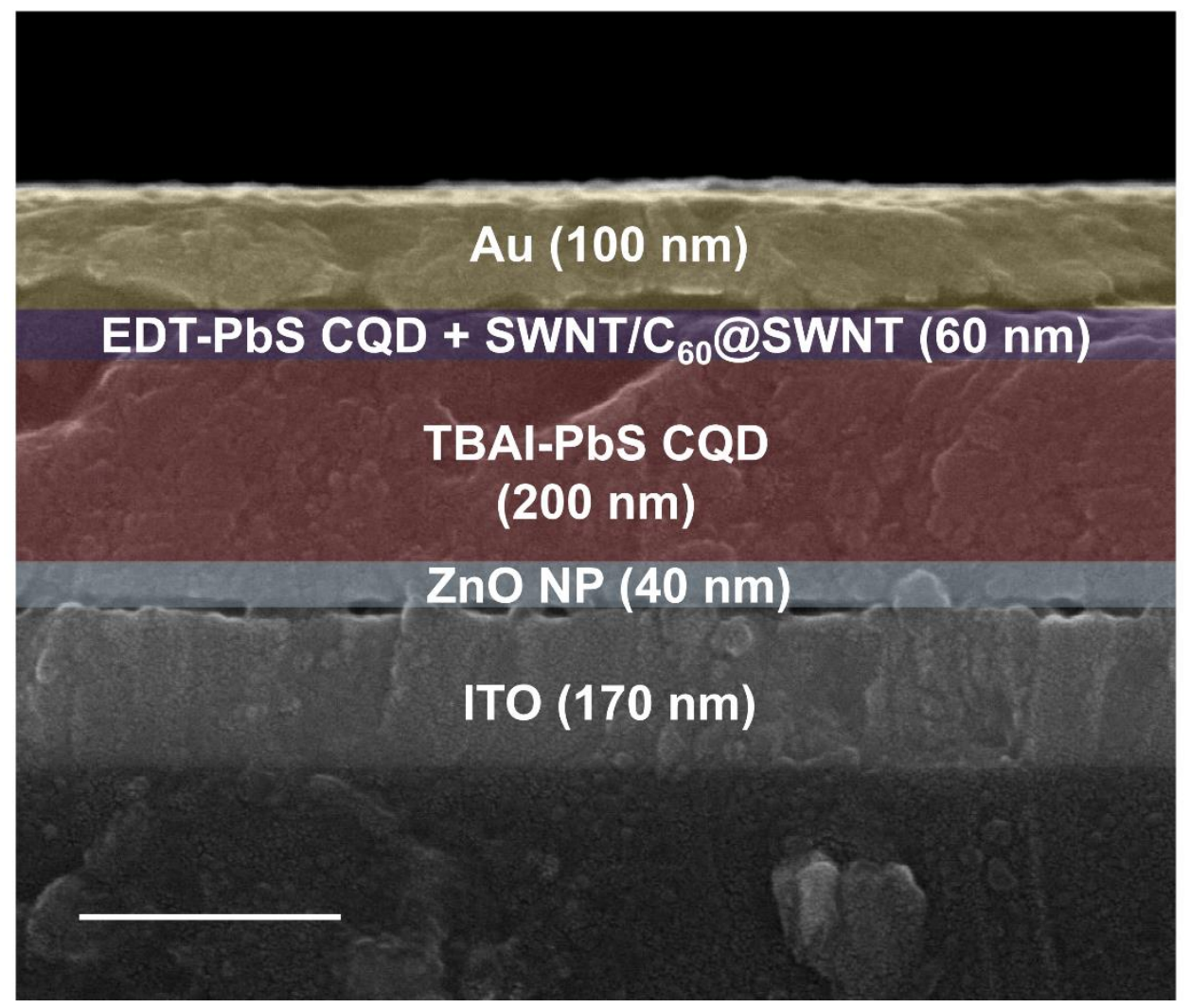

Figure S13. Representative cross-sectional SEM image of a CQDPV (scale bar: $300 \mathrm{~nm}$ ). 
(a)

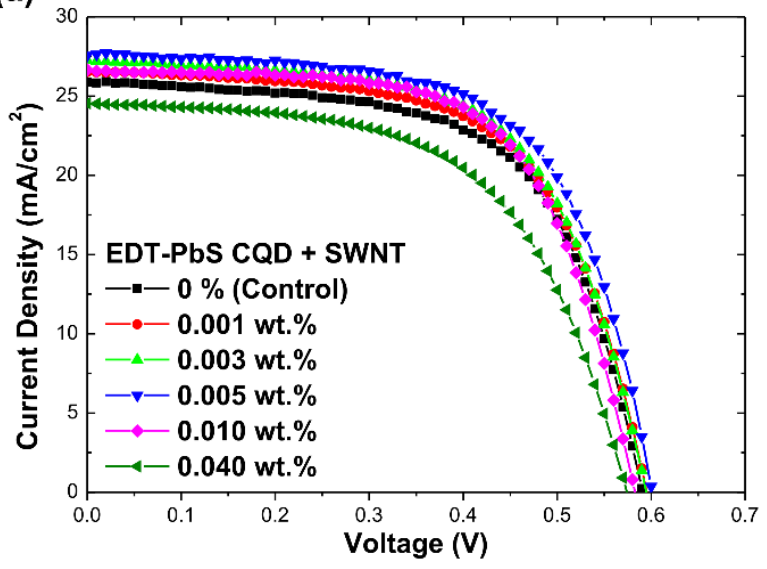

(b)

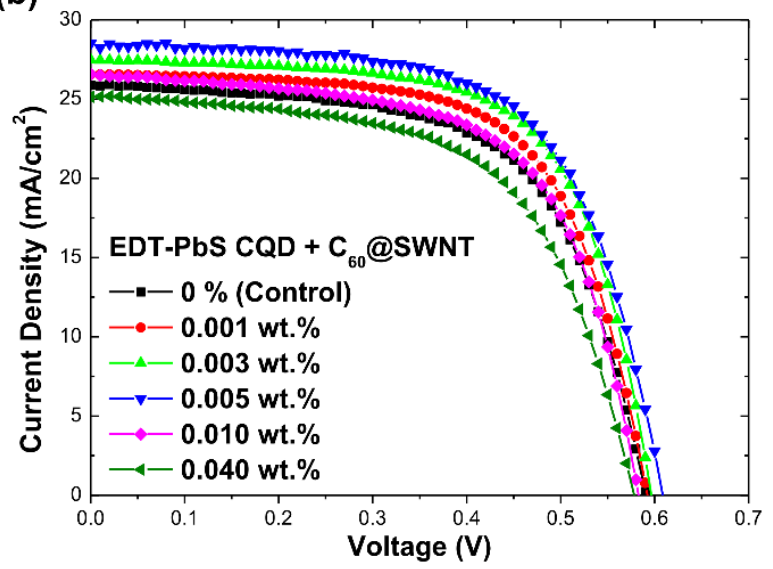

Figure S14. $J-V$ curves of control CQDPVs and samples with various concentrations of (a) pristine SWNT and (b) C60@SWNT. 
(a)

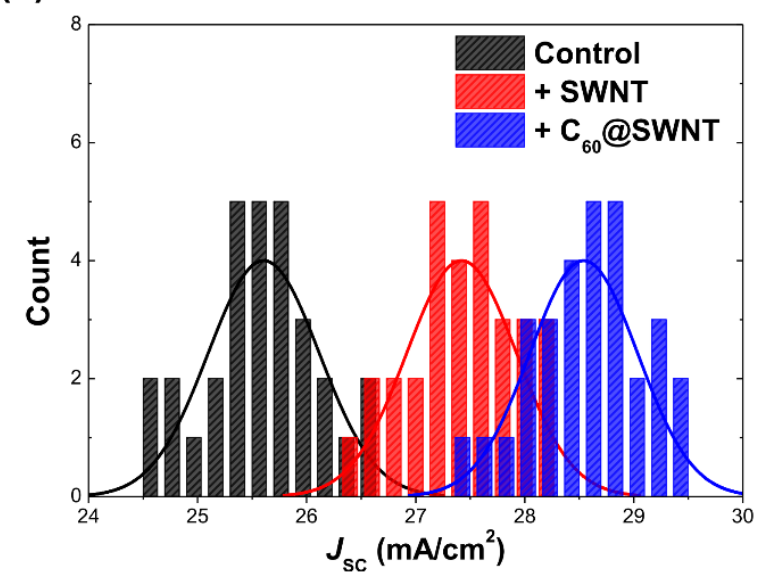

(c)

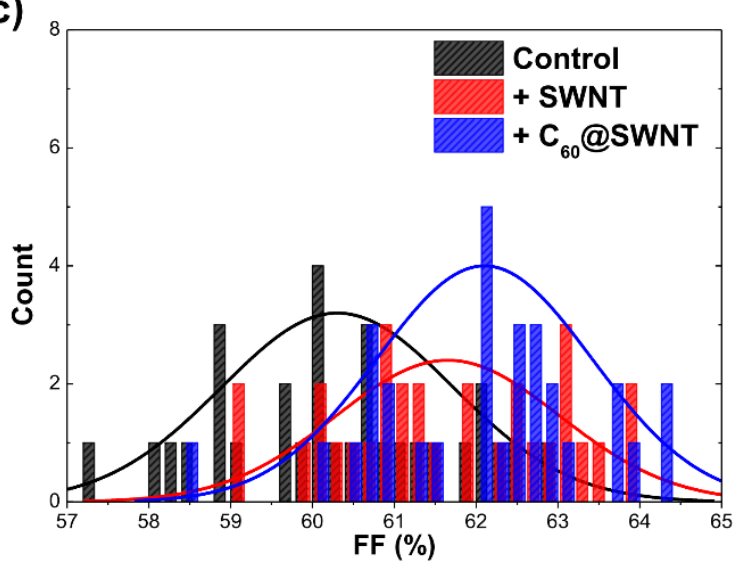

(b)

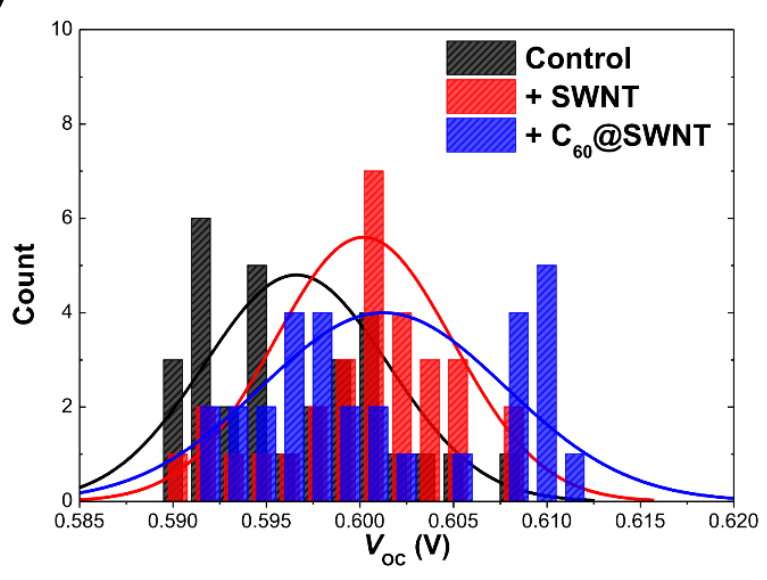

(d)

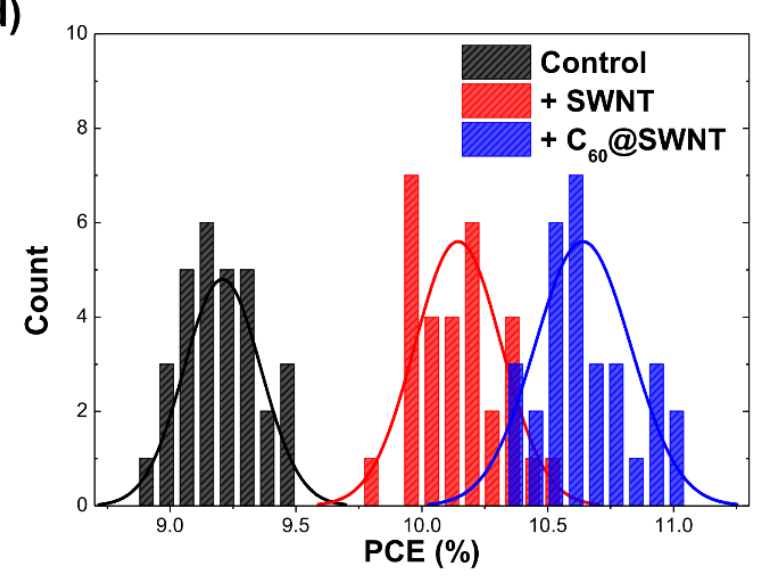

Figure S15. Statistical histograms of the CQDPVs performance based on 30 samples for each configuration: (a) $J_{\mathrm{SC}}$, (b) $V_{\mathrm{OC}}$, (c) FF, and (d) PCE 
(a)

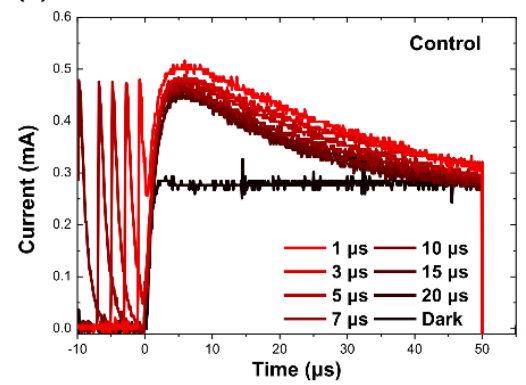

(d)

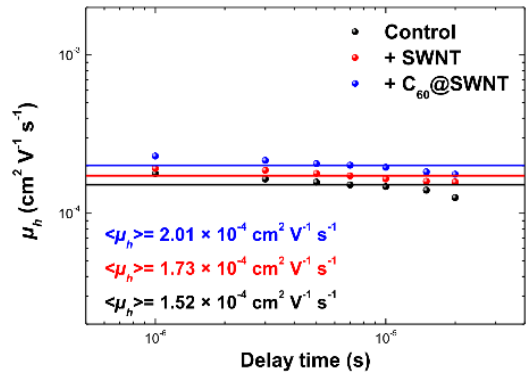

(b)

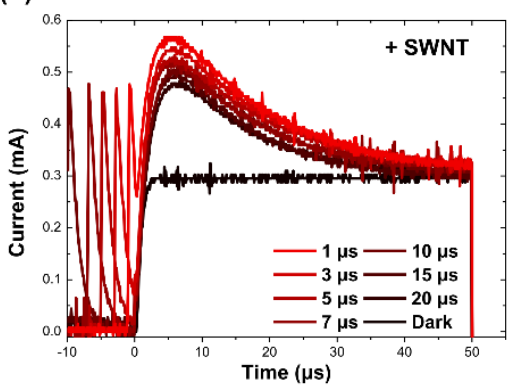

(c)

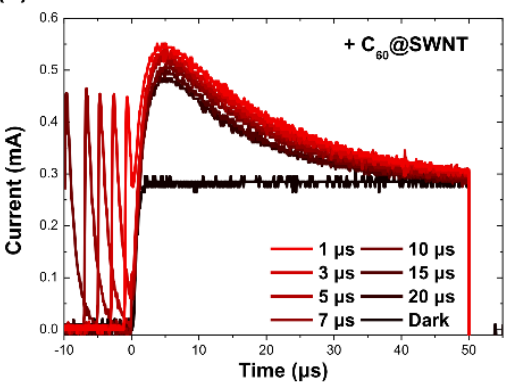

(e)

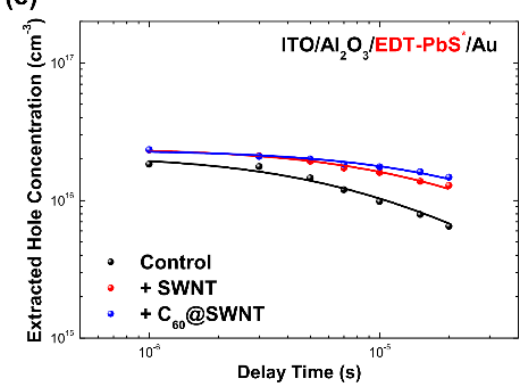

Figure S16. Hole-selective photo-CELIV transient profiles of the (a) control film, and films incorporating (b) SWNTs and (c) $\mathrm{C}_{60} @ \mathrm{SWNT}$. Estimated (d) $\mu_{\mathrm{h}}$ and (e) hole concentration from the EDT-PbS CQD films obtained from hole-selective photo-CELIV measurement. 


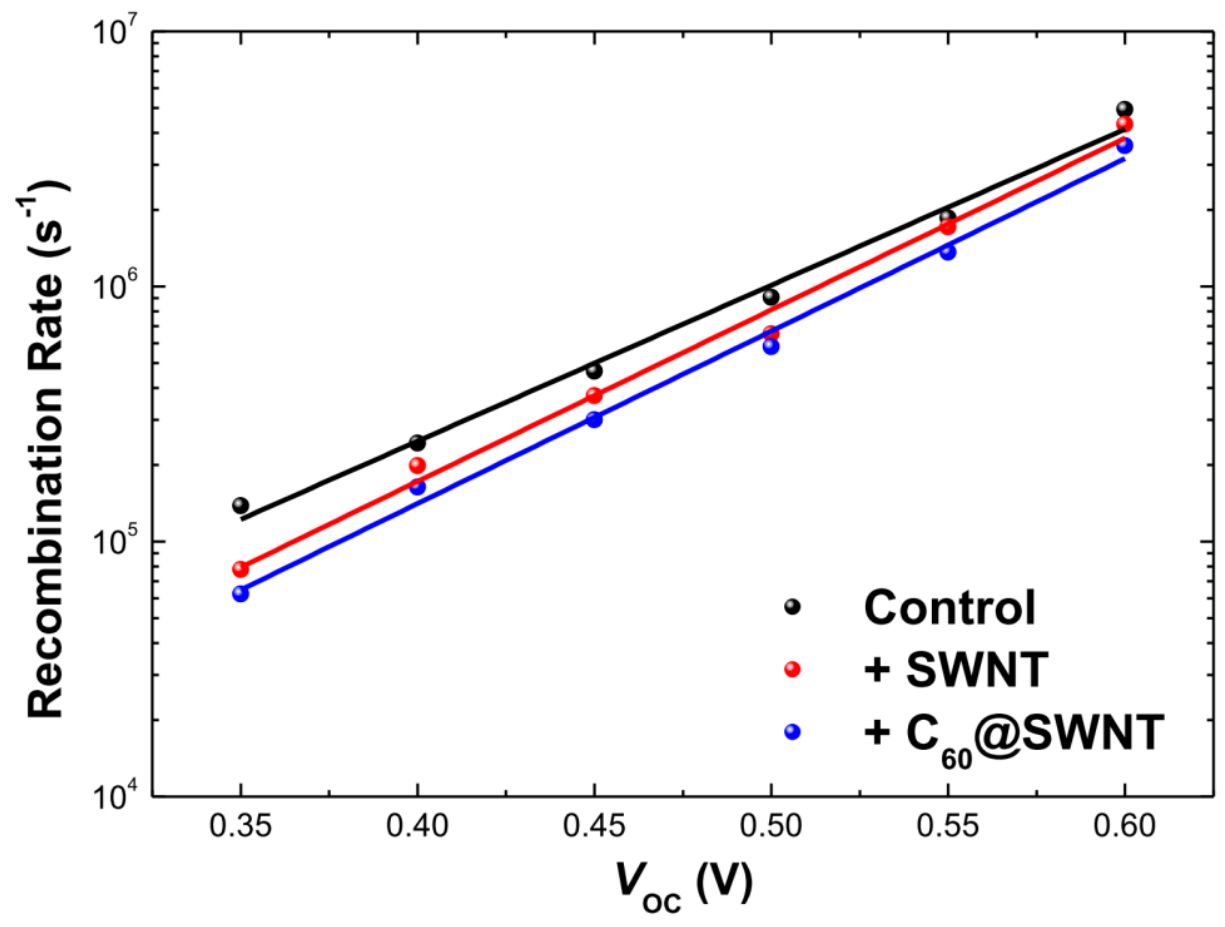

Figure S17. Recombination rates of the CQDPVs with respect to $V_{\mathrm{OC}}$ determined by the TPV measurements. 


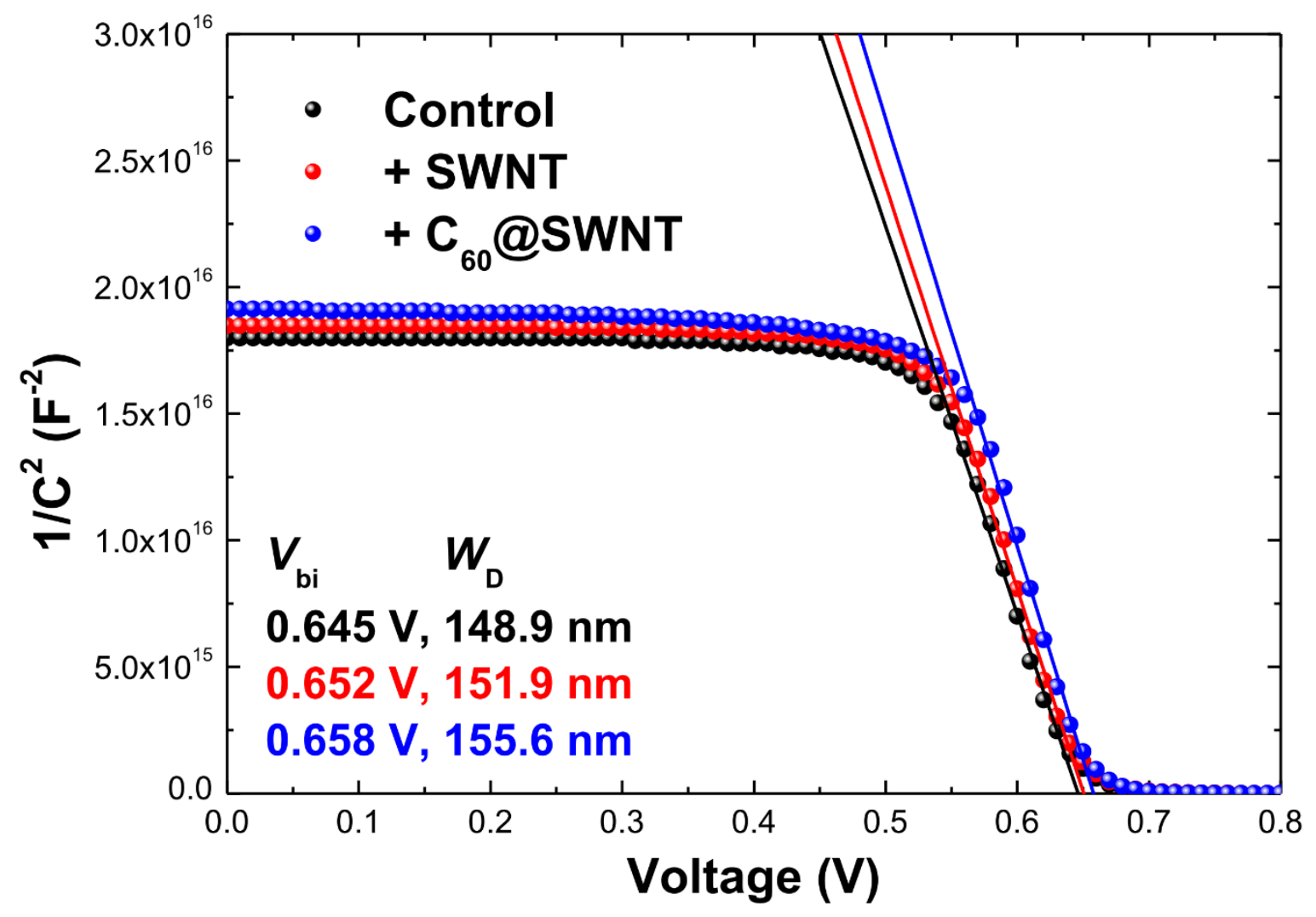

Figure S18. Mott-Schottky plots of the CQDPVs. The estimated $V_{\text {bi }}$ and $W_{D}$ of the CQDPVs are labeled. 
Table S1. Energy levels of the EDT-PbS CQD films

\begin{tabular}{|c|c|c|c|c|c|}
\hline Configuration & $\begin{array}{c}\text { Band gap } \\
(\mathrm{eV})\end{array}$ & $\begin{array}{c}E_{\mathrm{F}} \\
(\mathrm{eV})\end{array}$ & $\begin{array}{c}E_{\mathrm{F}}-E_{\mathrm{V}} \\
(\mathrm{eV})\end{array}$ & $\begin{array}{c}E_{\mathrm{C}} \\
(\mathrm{eV})\end{array}$ & $\begin{array}{c}E_{\mathrm{V}} \\
(\mathrm{eV})\end{array}$ \\
\hline Control & 1.29 & -4.41 & 0.45 & -3.57 & -4.86 \\
\hline+ SWNT & 1.29 & -4.45 & 0.42 & -3.58 & -4.87 \\
\hline$+\mathrm{C}_{60} @ \mathrm{SWNT}$ & 1.29 & -4.51 & 0.39 & -3.61 & -4.90 \\
\hline
\end{tabular}

Table S2. Time-resolved PL fitting results

\begin{tabular}{|c|c|c|c|c|c|c|c|}
\hline Configuration & $A_{1}$ & $\begin{array}{c}\tau_{1} \\
(\mathrm{~ns})\end{array}$ & $\begin{array}{c}A_{2} \\
(\mathrm{~ns})\end{array}$ & $\begin{array}{c}\tau_{2} \\
A_{3}\end{array}$ & $\begin{array}{c}\tau_{\tau} \\
(\mathrm{ns})\end{array}$ \\
\hline Control & 0.73 & 3.00 & 0.22 & 1.66 & 0.05 & 14.82 & $\mathbf{1 . 6 6}$ \\
\hline+ SWNT & 0.61 & 2.71 & 0.33 & 0.51 & 0.06 & 16.05 & $\mathbf{1 . 3 2}$ \\
\hline+ C60@SWNT & 0.58 & 2.56 & 0.37 & 0.44 & 0.05 & 14.98 & $\mathbf{1 . 1 7}$ \\
\hline
\end{tabular}

${ }^{a}$ The average lifetime was estimated from the equation: $\left\langle\tau>=\Sigma\left(A_{\mathrm{i}} \tau_{\mathrm{i}}\right)^{2} / \Sigma\left(A_{\mathrm{i}} \tau_{\mathrm{i}}\right)\right.$ 
Table S3. Photovoltaic performances of CQDPVs for various SWNT (or C60@SWNT) concentrations

\begin{tabular}{|c|c|c|c|c|}
\hline \multicolumn{5}{|c|}{ EDT-PbS + SWNT } \\
\hline $\begin{array}{l}\text { Concentration } \\
(x \text { wt.\%) }\end{array}$ & $V_{\mathrm{OC}}(\mathrm{V})$ & $J_{\mathrm{SC}}\left(\mathrm{mA} / \mathrm{cm}^{2}\right)$ & $F F(\%)$ & PCE (\%) \\
\hline$x=0($ Normal $)$ & $\begin{array}{l}0.5969 \pm 0.005 \\
(0.5908)\end{array}$ & $\begin{array}{l}25.603 \pm 0.52 \\
(25.867)\end{array}$ & $\begin{array}{c}60.30 \pm 1.42 \\
(62.29)\end{array}$ & $\begin{array}{l}9.21 \pm 0.15 \\
(9.52)\end{array}$ \\
\hline$x=0.001$ wt. $\%$ & $\begin{array}{l}0.5923 \pm 0.004 \\
(0.5952)\end{array}$ & $\begin{array}{l}26.038 \pm 0.71 \\
(26.530)\end{array}$ & $\begin{array}{l}61.19 \pm 1.63 \\
(60.51)\end{array}$ & $\begin{array}{l}9.44 \pm 0.21 \\
\quad(9.55)\end{array}$ \\
\hline$x=0.003$ wt. $\%$ & $\begin{array}{l}0.5950 \pm 0.004 \\
(0.5948)\end{array}$ & $\begin{array}{l}26.617 \pm 0.57 \\
(27.259)\end{array}$ & $\begin{array}{l}61.69 \pm 1.29 \\
(61.24)\end{array}$ & $\begin{array}{l}9.76 \pm 0.18 \\
(9.93)\end{array}$ \\
\hline$x=0.005$ wt. $\%$ & $\begin{array}{c}0.6002 \pm 0.005 \\
(0.6011)\end{array}$ & $\begin{array}{c}27.421 \pm 0.51 \\
(27.559)\end{array}$ & $\begin{array}{c}61.65 \pm 1.37 \\
(63.31)\end{array}$ & $\begin{array}{c}10.14 \pm 0.17 \\
(10.49)\end{array}$ \\
\hline$x=0.010 \mathrm{wt} . \%$ & $\begin{array}{c}0.5870 \pm 0.008 \\
(0.5828)\end{array}$ & $\begin{array}{l}26.288 \pm 0.63 \\
(26.654)\end{array}$ & $\begin{array}{l}62.00 \pm 1.50 \\
(63.19)\end{array}$ & $\begin{array}{l}9.57 \pm 0.23 \\
\quad(9.82)\end{array}$ \\
\hline$x=0.040$ wt. $\%$ & $\begin{array}{c}0.5752 \pm 0.006 \\
(0.5736)\end{array}$ & $\begin{array}{c}24.411 \pm 0.48 \\
(24.535)\end{array}$ & $\begin{array}{c}57.11 \pm 0.98 \\
(57.19)\end{array}$ & $\begin{array}{c}8.01 \pm 0.12 \\
(8.05)\end{array}$ \\
\hline \multicolumn{5}{|c|}{ EDT-PbS + C60@SWNT } \\
\hline $\begin{array}{c}\text { Concentration } \\
(x \text { wt. } \%)\end{array}$ & $V_{\mathrm{OC}}(\mathrm{V})$ & $J_{\mathrm{SC}}\left(\mathrm{mA} / \mathrm{cm}^{2}\right)$ & $F F(\%)$ & PCE $(\%)$ \\
\hline$x=0($ Normal $)$ & $\begin{array}{c}0.5969 \pm 0.005 \\
(0.5908)\end{array}$ & $\begin{array}{c}25.603 \pm 0.52 \\
(25.867)\end{array}$ & $\begin{array}{c}60.30 \pm 1.42 \\
(62.29)\end{array}$ & $\begin{array}{c}9.21 \pm 0.15 \\
(9.52)\end{array}$ \\
\hline$x=0.001$ wt. $\%$ & $\begin{array}{l}0.5902 \pm 0.004 \\
(0.5924)\end{array}$ & $\begin{array}{l}26.225 \pm 0.88 \\
(26.548)\end{array}$ & $\begin{array}{l}62.11 \pm 1.14 \\
(63.53)\end{array}$ & $\begin{array}{l}9.61 \pm 0.19 \\
(9.99)\end{array}$ \\
\hline$x=0.003 \mathrm{wt} . \%$ & $\begin{array}{l}0.5928 \pm 0.004 \\
(0.5965)\end{array}$ & $\begin{array}{l}27.405 \pm 0.23 \\
(27.490)\end{array}$ & $\begin{array}{c}63.49 \pm 1.89 \\
(65.17)\end{array}$ & $\begin{array}{c}10.31 \pm 0.27 \\
(10.68)\end{array}$ \\
\hline$x=0.005$ wt. $\%$ & $\begin{array}{c}0.6013 \pm 0.007 \\
(0.6085)\end{array}$ & $\begin{array}{c}28.503 \pm 0.51 \\
(28.507)\end{array}$ & $\begin{array}{c}62.10 \pm 1.32 \\
(63.54)\end{array}$ & $\begin{array}{c}10.64 \pm 0.19 \\
(11.04)\end{array}$ \\
\hline$x=0.010$ wt. $\%$ & $\begin{array}{c}0.5880 \pm 0.005 \\
(0.5828)\end{array}$ & $\begin{array}{c}26.011 \pm 0.49 \\
(26.573)\end{array}$ & $\begin{array}{c}61.21 \pm 1.17 \\
(62.24)\end{array}$ & $\begin{array}{c}9.36 \pm 0.15 \\
(9.64)\end{array}$ \\
\hline$x=0.040 \mathrm{wt} . \%$ & $\begin{array}{c}0.5777 \pm 0.004 \\
(0.5782)\end{array}$ & $\begin{array}{l}24.728 \pm 0.46 \\
(25.143)\end{array}$ & $\begin{array}{l}59.10 \pm 0.97 \\
(59.04)\end{array}$ & $\begin{array}{c}8.44 \pm 0.14 \\
(8.58)\end{array}$ \\
\hline
\end{tabular}


Table S4. Dynamic parameters of the EDT-PbS films obtained by photo-CELIV measurements

\begin{tabular}{|c|c|c|c|c|}
\hline Configuration & $\begin{array}{c}<\mu_{\mathrm{h}}> \\
\left(\mathrm{cm}^{-2} \mathrm{~V}^{-1} \mathrm{~s}^{-1}\right)\end{array}$ & $\begin{array}{c}p_{0} \\
\left(\mathrm{~cm}^{-3}\right)\end{array}$ & $\begin{array}{c}\tau_{\mathrm{B}} \\
(\mu \mathrm{s})\end{array}$ & $\begin{array}{c}L_{\mathrm{D}} \\
(\mathrm{nm})\end{array}$ \\
\hline Control & $1.52( \pm 0.24) \times 10^{-4}$ & $2.14( \pm 0.22) \times 10^{16}$ & $9.30( \pm 0.88)$ & $60.3( \pm 7.6)$ \\
\hline+ SWNT & $1.78( \pm 0.23) \times 10^{-4}$ & $2.41( \pm 0.25) \times 10^{16}$ & $20.28( \pm 0.83)$ & $95.0( \pm 8.2)$ \\
\hline+ C60@SWNT & $2.01( \pm 0.27) \times 10^{-4}$ & $2.33( \pm 0.23) \times 10^{16}$ & $31.85( \pm 0.89)$ & $128.3( \pm 10.5)$ \\
\hline
\end{tabular}

\section{References}

1. Takenobu, T.; Takano, T.; Shiraishi, M.; Murakami, Y.; Ata, M.; Kataura, H.; Achiba, Y.; Iwasa, Y. Stable and Controlled Amphoteric Doping by Encapsulation of Organic Molecules Inside Carbon Nanotubes. Nat. Mater. 2003, 2, 683-688.

2. Yang, J.; Lee, J.; Lee, J.; Yi, W. Conductivity and Field Emission Enhancement of $\mathrm{C}_{60}-$ Encapsulated Single-Walled Carbon Nanotubes. Diamond Relat. Mater. 2018, 89, 273-281.

3. Hines, M. A.; Scholes, G. D. Colloidal PbS Nanocrystals with Size-Tunable Near-Infrared Emission: Observation of Post-Synthesis Self-Narrowing of the Particle Size Distribution. Adv. Mater. 2003, 15, 1844-1849.

4. Dai, X.; Zhang, Z.; Jin, Y.; Niu, Y.; Cao, H.; Liang, X.; Chen, L.; Wang, J.; Peng, X. SolutionProcessed, High-Performance Light-Emitting Diodes Based on Quantum Dots. Nature 2014, 515, 96-99.

5. Willis, S. M.; Cheng, C.; Assender, H. E.; Watt, A. A. R. The Transitional Heterojunction Behavior of PbS/ZnO Colloidal Quantum Dot Solar Cells. Nano Lett. 2012, 12, 1522-1526. 
6. Lan, X.; Voznyy, O.; Kiani, A.; de Arquer, F. P. G.; Abbas, A. S.; Kim, G.; Liu, M.; Yang, Z.; Walters, G.; Xu, J.; Yuan, M.; Ning, Z.; Fan, F.; Kanjanaboos, P.; Kramer, I.; Zhitomirsky, D.; Lee, P.; Perelgut, A.; Hoogland, S.; Sargent, E. H. Passivation Using Molecular Halides Increases Quantum Dot Solar Cell Performance. Adv. Mater. 2016, 28, 299-304.

7. Aqoma, H.; Mubarok, M. A.; Hadmojo, W. T.; Lee, E.; Kim, T.; Ahn, T. K.; Oh, S.; Jang, S. High-Efficiency Photovoltaic Devices Using Trap-Controlled Quantum-Dot Ink Prepared via Phase-Transfer Exchange. Adv. Mater. 2017, 29, 1605756.

8. Brown, P. R.; Lunt, R.; Zhao, N.; Osedach, T. P.; Wanger, D. D.; Chang, L. Y.; Bawendi, M.

G.; Bulovic, V. Improved Current Extraction from $\mathrm{ZnO} / \mathrm{PbS}$ Quantum Dot Heterojunction Photovoltaics Using a $\mathrm{MoO}_{3}$ Interfacial Layer. Nano Lett. 2011, 11, 2955-2961. 